\title{
TU/e EmonOWEN

\section{Predicting the rate effects on hooked-end fiber pullout performance from Ultra-High Performance Concrete (UHPC)}

Citation for published version (APA):

Cao, Y., Yu, Q., Brouwers, J., \& Chen, W. (2019). Predicting the rate effects on hooked-end fiber pullout performance from Ultra-High Performance Concrete (UHPC). Cement and Concrete Research, 120, 164-175. https://doi.org/10.1016/j.cemconres.2019.03.022

\section{Document license: \\ TAVERNE}

DOI:

10.1016/j.cemconres.2019.03.022

Document status and date:

Published: 01/06/2019

\section{Document Version:}

Publisher's PDF, also known as Version of Record (includes final page, issue and volume numbers)

\section{Please check the document version of this publication:}

- A submitted manuscript is the version of the article upon submission and before peer-review. There can be important differences between the submitted version and the official published version of record. People interested in the research are advised to contact the author for the final version of the publication, or visit the $\mathrm{DOI}$ to the publisher's website.

- The final author version and the galley proof are versions of the publication after peer review.

- The final published version features the final layout of the paper including the volume, issue and page numbers.

Link to publication

\section{General rights}

Copyright and moral rights for the publications made accessible in the public portal are retained by the authors and/or other copyright owners and it is a condition of accessing publications that users recognise and abide by the legal requirements associated with these rights.

- Users may download and print one copy of any publication from the public portal for the purpose of private study or research.

- You may not further distribute the material or use it for any profit-making activity or commercial gain

- You may freely distribute the URL identifying the publication in the public portal.

If the publication is distributed under the terms of Article 25fa of the Dutch Copyright Act, indicated by the "Taverne" license above, please follow below link for the End User Agreement:

www.tue.nl/taverne

Take down policy

If you believe that this document breaches copyright please contact us at:

openaccess@tue.nl

providing details and we will investigate your claim. 


\title{
Predicting the rate effects on hooked-end fiber pullout performance from Ultra-High Performance Concrete (UHPC)
}

\author{
Y.Y.Y. Cao ${ }^{\mathrm{a}}$, Q.L. Yu ${ }^{\mathrm{a}, *}$, H.J.H. Brouwers ${ }^{\mathrm{a}, \mathrm{b}}$, W. Chen ${ }^{\mathrm{b}, *}$ \\ ${ }^{\text {a }}$ Department of the Built Environment, Eindhoven University of Technology, P.O. Box 513, 5600 MB Eindhoven, the Netherlands \\ ${ }^{\mathrm{b}}$ State Key Lab of Silicate Materials for Architectures, Wuhan University of Technology, Wuhan 430070, PR China
}

\section{A R T I C L E I N F O}

\section{Keywords:}

Rate effects

Single-fiber pullout

Hooked-end steel fiber

Ultra-High Performance Concrete

Prediction model

\begin{abstract}
A B S T R A C T
The rate-dependent pullout performances of hooked-end fibers embedded in a UHPC matrix are investigated. Pullout load-slip relations corresponding to loading rates from $5 \mathrm{~mm} / \mathrm{min}$ to $1000 \mathrm{~mm} / \mathrm{min}$ and dynamic pullout responses are analyzed. The results show pullout energy is more rate sensitive than peak pullout load, e.g. with an embedded length of $15 \mathrm{~mm}$, the dynamic increase factors (DIFs) under $1000 \mathrm{~mm} / \mathrm{min}$ are 1.46 and 1.22 , respectively. The rate effects on the pullout load are more prominent with a smaller embedded length due to the smaller concrete confinement, therefore the higher cracking potential. Further, a new analytical model to predict the dynamic peak pullout loads covering the loading rates from quasi-static to intermediate levels is proposed and validated. The present findings reveal that the inertial effects related to the crack initiation and propagation in the fiber-matrix interface have significant influences on the rate dependent pullout behaviors, which contribute to the potential utilization of UHPFRC composite in resisting dynamic loadings.
\end{abstract}

\section{Introduction}

Security problems of specialized structures, e.g. nuclear power plants and high rise buildings, have become critical considerations. Having a potentially high risk of being exposed to terrorist attacks or accidental impacts, these structures require suitable construction materials to withstand dynamic loadings. Ultra-High Performance Fiber Reinforced Concrete (UHPFRC) is one of the latest developments in concrete industry. The very low water to binder ratio and the high particle packing density of the matrix [1-3] result in its extremely high compressive strength (e.g. in excess of $150 \mathrm{MPa}$ ), and the addition of steel fibers benefits its excellent energy absorption capacity. Such superior mechanical properties of UHPFRC overcome the brittle nature of conventional concrete that causes an inherent poor behavior under impact [4], therefore, making UHPFRC a promising material for impact and blast resistant constructions in both civil and military fields [5-7].

As a result of strain rate effects, the behavior of cement based materials subjected to dynamic loadings usually differs from that under static loadings, e.g. the strength, the failure mode, and the crack development velocity can be affected by the external loading rate [8]. Strain rate regime divisions and the corresponding loading scenarios are given in Fig. 1 [9,10]. For the design and analysis of impact-resistant UHPFRC, its dynamic response should be understood. Wille et al. [11] investigated the uniaxial tensile behavior of UHPFRC under strain rates from 0.0001 to $0.1 \mathrm{~s}^{-1}$, and rate effects were observed on the cracking stress, tensile strength, softening strain, and energy absorption capacity. Millard et al. [12] conducted drop-hammer tests to obtain the dynamic increase factors (DIFs) of UHPFRC. Significant DIFs of the flexural strength were reported in their study at strain rates between 0.1 and $10 \mathrm{~s}^{-1}$, and the values were affected by fiber contents. Tan et al. [13] analyzed the dynamic stress-strain performance of UHPFRC under split-Hopkinson bar impact at strain rates from 30 to $60 \mathrm{~s}^{-1}$. The test results revealed that loading rates have great influences on both the concrete strength and the toughness.

Incorporating fibers in Ultra-High Performance Concrete (UHPC) matrix attributes to the significant enhancement of the composite toughness, and it is associated with not only the total amount of fibers but also the bond relationship between the individual fiber and the matrix. Moreover, the increase of the UHPFRC flexural strength under dynamic loadings is reported to be closely related to the interfacial bond characteristics [14]. As a foundation to analyze the fiber-matrix bond, single fiber pullout experiments provide basic information about the interface properties as well as the stress transfer mechanisms between the fiber and the matrix [15]. Given that steel fibers, UHPC matrix and the interface in between are rate sensitive, the pullout performances of the steel fiber embedded in UHPC are thus expected to be rate dependent [16]. Nevertheless, insufficient investigations are available concerning the dynamic fiber pullout processes, i.e. most

\footnotetext{
* Corresponding authors.

E-mail addresses: q.yu@bwk.tue.nl (Q.L. Yu), chen.wei@whut.edu.cn (W. Chen).
} 


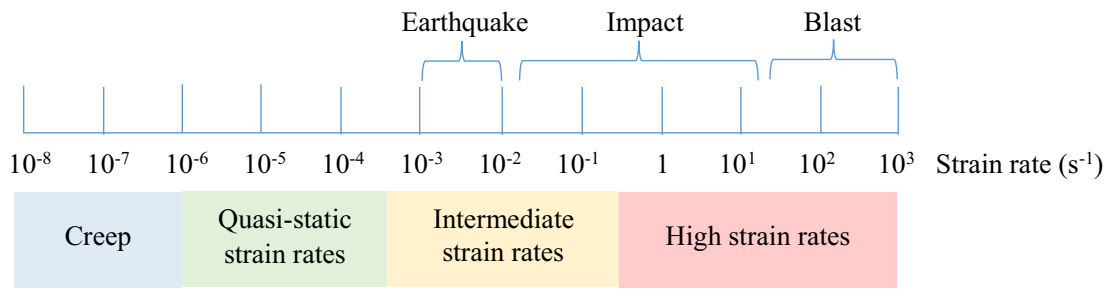

emphasis has been on the quasi-static responses [17]. Among the limited studies, Banthia and Trottier [16] performed pullout tests of deformed steel fibers from cementitious matrices and concluded that the fibers can sustain a higher pullout resistance and pullout energy under dynamic conditions than the static ones. Abu-Lebdeh et al. [18] compared the rate dependency of steel fibers embedded in a very high strength concrete and found that the rate-dependent pullout responses of deformed fibers vary with the matrix strength. Xu et al. [19] investigated the effects of the fiber type and orientation angle on the rate sensitivity by conducting experiments of steel fibers pulled out from UHPC at loading rates ranging from $0.025 \mathrm{~mm} / \mathrm{s}$ to $25 \mathrm{~mm} / \mathrm{s}$. The study demonstrated that the half-hooked fiber exhibits the highest loading rate dependency with respect to pullout load and an inclination angle of $20^{\circ}$ leads to a more remarkable rate effect. Tai et al. [20] and Tai and EI-Tawil [21] investigated the pullout behaviors of straight and deformed steel fibers in UHPC at loading rates $0.018 \mathrm{~mm} / \mathrm{s}$ to $1800 \mathrm{~mm} / \mathrm{s}$, and found that the pullout responses of both straight and deformed steel fibers are rate sensitive.

Since traditional UHPFRC only contains fine aggregates in the matrix, reinforcements in UHPFRC are usually short straight steel fibers. Nevertheless, recent research reveal that incorporating appropriate content of hooked-end steel fibers in UHPFRC endows superior properties with respect to post cracking strength, strain capacity and multiple cracking behavior than the straight-fiber-reinforced UHPFRC [22-25]. Also, UHPFRC incorporated with hooked-end fibers shows a capacity in resisting low-velocity pendulum impacts [4], indicating its potential to withstand dynamic loadings at intermediate strain rates (see Fig. 1). These tendencies make the understanding of dynamic pullout behaviors of hooked-end steel fibers embedded in UHPC matrix an important issue.

However, contradictions exist about the rate effects on the pullout performances of hooked-end fiber. For example, Kim et al. [26] described the pullout test results of hooked-end and twisted fibers at loading rates from $0.018 \mathrm{~mm} / \mathrm{s}$ to $18 \mathrm{~mm} / \mathrm{s}$. It is reported that while the twisted fiber shows a rate sensitivity, the pullout behavior of the hooked-end steel fiber is rate-independent, which is contrary to the observations in other studies [18-21]. Among the literature in which rate effects on the hooked-end fibers pullout responses are observed, the level of rate sensitivity also varies [19]. For instance, Xu et al. [19] found that the half-hooked fiber has the strongest rate dependency compared to the smooth and twisted fibers; on the contrary, Tai et al. [20] showed similar pullout load DIFs for the hooked-end fiber and the straight fiber with a similar diameter; conversely, a following study in ref. [21] demonstrated that the hooked-end fiber is less rate sensitive than the straight fiber with the same diameter. This discrepancy indicates the unclearness concerning the mechanisms behind the ratedependent pullout behavior. By comparing the test results of hookedend fibers with different embedded lengths in several literature, $\mathrm{Xu}$ et al. [19] supposed that the fiber embedded length may be a significant influencing factor on rate effects. Nevertheless, this supposition is derived by summarizing independent researches with different concrete matrices and the variables are quite complex. Abu-Lebdeh et al. [18] investigated the rate sensitivities of fiber pullout behaviors with different embedded lengths, and their study confirmed that the rate dependency of the hooked-end fiber varies with the embedded length. However, only two pullout rates, i.e. $1.26 \mathrm{~mm} / \mathrm{min}$ and $1524 \mathrm{~mm} / \mathrm{min}$,
Fig. 1. Strain rate regimes and corresponding loading scenarios. were involved in their study whereas the pullout behaviors at the inbetween loading rates are unclear and the mechanisms leading to the influences of the embedded length were not addressed.

As mentioned above, research on the dynamic pullout behaviors of hooked-end steel fiber have been performed mostly on experimental basis [18-21,25]. Apart from these experimental investigations, little attention has been paid to developing analytical models to predict the dynamic response. To the best of the authors' knowledge, there is yet no analytical model available to predict the pullout resistance of hookedend steel fiber embedded in UHPC under dynamic loadings, i.e. previous analytical models for hooked-end steel fiber can only be applied for the quasi-static loading condition [27-30]. Alwan et al. [27] developed a model to predict the quasi-static pullout performance of hooked steel fibers by applying a frictional pulley to simulate the hook action. Sujivorakul and Waas [28] considered the mechanical anchorage of the hook as a nonlinear spring at the end of the fiber and proposed a quasi-static model for hooked-end fibers by extending the one for straight fibers. Laranjeira et al. [29] experimentally evaluated the contribution of the hook under quasi-static loading and developed an analytical model for inclined hooked-end steel fibers based on the experimental data. By considering the repetitive bending and unbending of deformed fibers during the pullout process, Zile and Zile [30] proposed a model to investigate the influence of fiber geometry on quasistatic pullout performances, a good agreement was observed between their model prediction and the experimental results.

This study is motivated by the insufficient understanding of the relationship between the rate-effects and pullout performances of hooked-end fiber embedded in UHPC, as well as the lack of dynamic prediction model. Firstly, single fiber pullout experiments of a hookedend steel fiber with different embedded lengths under dynamic loading rates from $5 \mathrm{~mm} / \mathrm{min}$ to $1000 \mathrm{~mm} / \mathrm{min}$ are conducted, the rate range of which includes a broad band of frequencies that are excited by earthquakes and some typical impacts in reality. Together with the detailed background knowledge concerning the rate effects of cement based material, mechanisms that affect the rate sensitivity of the fiber-matrix bond are analyzed and the influences of the embedded length on the rate-dependency are explained. Subsequently, a new analytical model to predict the dynamic pullout resistance of the hooked-end steel fiber in UHPC matrix at quasi-static to intermediate rates is proposed and validated. The results obtained from this study shed light on understanding the rate-dependent pullout performances of hooked-end steel fibers embedded in UHPC matrix, and contribute to the improvements of UHPFRC dynamic performances.

\section{Materials and experiments}

\subsection{Steel fibers and UHPC matrix}

In this study, Dramix RC-80/30-BP fiber is used for the single fiber pullout tests. The basic geometry and mechanical parameters of the fiber are given in Fig. 2. The fiber is brass coated. Two embedded lengths are investigated in this study, i.e. $l_{\mathrm{e}}=10 \mathrm{~mm}$ and $15 \mathrm{~mm}$.

The UHPC matrix for the pullout test is based on the recipe described in refs. [31,32] (Table 1), which is designed applying the Brouwers method [33]. Raw materials used are Portland Cement CEM I 52.5 R (CEM), micro-silica (mS), limestone powder (LP), sand 0-2 (S), 


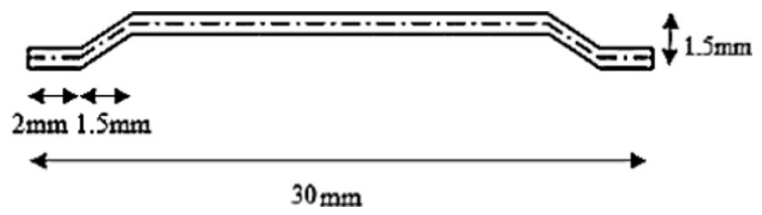

Table 1

Recipe of UHPC matrix [31,32].

\begin{tabular}{ll}
\hline Materials & Proportion \\
\hline Portland Cement CEM I 52.5 R & 1 \\
Micro-silica & 0.067 \\
Limestone powder & 0.267 \\
Sand 0-2 & 1.281 \\
Basalts aggregate 1-3 & 0.854 \\
Water & 0.267 \\
Superplasticizer & 0.016 \\
\hline
\end{tabular}

basalts aggregate 1-3 (BA), water (W), and PCE superplasticizer (SP). The static compressive strength of the UHPC at 28 days is $156 \mathrm{MPa}$. More detailed information about the mix design, fresh and hardened properties of the UHPC matrix can be found in ref. [31].

\subsection{Casting of specimens}

The mixing of the UHPC matrix is conducted at room temperature of $20 \pm 1{ }^{\circ} \mathrm{C}$, following the procedure below: dry mix of all the powders, sands and basalt aggregates for $2 \mathrm{~min}$; sequentially add $75 \%$ water and mix for another $2 \mathrm{~min}$; add the superplasticizer and the remaining water, then mix at low speed for $2 \mathrm{~min}$ and high speed for $4 \mathrm{~min}$. After mixing, the self-compacting UHPC mixture is poured into one half of the dog-bone shaped molds (Fig. 3a), in which a single hooked-end steel fiber is carefully held in place by hard foams with the desired embedded length. The cast specimens are covered with plastic films and stored at room temperature for $24 \mathrm{~h}$. Then they are demolded and cured in water under room temperature for an additional 27 days. All specimens are tested under surface dry condition at the age of 28 days.

\subsection{Fiber pullout test setup and procedure}

The single fiber pullout test is conducted using an Instron 5967 universal testing machine (Fig. 4). In order to reduce the grip confinement on the dog-bone shaped specimen, a round grip is applied to hold the concrete specimen. The free end of the steel fiber is tightly restrained by a specially designed aluminum grip, in which slippery is prevented. The pullout load is measured by a load cell with a capacity of $30 \mathrm{kN}$. By assuming that the elastic deformation of the steel fiber and the grips are small enough [32,34], the fiber slip is measured based on the vertical movement of the grip system.

The pullout tests are performed under displacement control. The pullout rates adopted are $5 \mathrm{~mm} / \mathrm{min}, 50 \mathrm{~mm} / \mathrm{min}, 500 \mathrm{~mm} / \mathrm{min}$ and
$1000 \mathrm{~mm} / \mathrm{min}$, and the corresponding strain rates are around $0.003 \mathrm{~s}^{-1}, 0.03 \mathrm{~s}^{-1}, 0.3 \mathrm{~s}^{-1}$ and $0.6 \mathrm{~s}^{-1}$ based on the dimension of the specimen. As suggested by the strain rate regimes plotted in Fig. 1, the smallest pullout rate in this study represents the quasi-static condition while the largest belongs to the intermediate level. To obtain reliable data, at least five specimens are tested to calculate the average value under each loading rate category. Examples of the averaged test data and the detailed procedure to obtain the average pullout load-slip curves are given in Appendix A.

\subsection{SEM observations}

Scanning electron microscopy (SEM) analysis is performed to investigate the mesoscopic interface structure between the steel fiber and the UHPC matrix. The sample preparation process for the SEM analysis can be briefly described as follows: (1) cutting. The planned studied regions are cut into small pieces from the air-dried specimens. (2) Epoxy resin coating. The samples are put in cylindrical rubber containers with the desired face parallel in the horizontal direction, and then impregnated with epoxy. (3) Polishing. After the epoxy is hardened, i.e. approximately $6 \mathrm{~h}$, the samples are polished using an auto polisher for 5 min with a 600 grit silicon carbide sand paper, and for another 5 min with an 800 grit silicon carbide sand paper.

\section{Rate dependency of cement based material}

\subsection{Rate effects on concrete tensile strength}

The rate dependent behavior of concrete material has been the subject of intensive investigations. Dynamic increase factor (DIF), i.e. the ratio of dynamic strength to static strength, is commonly used to gauge the nominal strength enhancement for engineering applications. The results from extensive tests have shown that concrete exhibits a strong rate sensitivity under tensile loads over a wide range of strain rates [35-38]. As demonstrated by previous studies [8,35], two distinct regimes appear in the tensile strength DIF, i.e. it tends from a moderate rate dependency at loading rates below a turning point of $1 \mathrm{~s}^{-1}$ to an excessive rate sensitivity at higher loading rates. The determination of the tensile strength DIF is recommended by the CEB-FIB Model Code [39] as:

$\mathrm{DIF}=\left(\frac{\dot{\varepsilon}_{\mathrm{t}}}{\dot{\varepsilon}_{\mathrm{t} 0}}\right)^{1.016 \delta}$ for $\dot{\varepsilon}_{\mathrm{t}} \leq 30 \mathrm{~s}^{-1}$

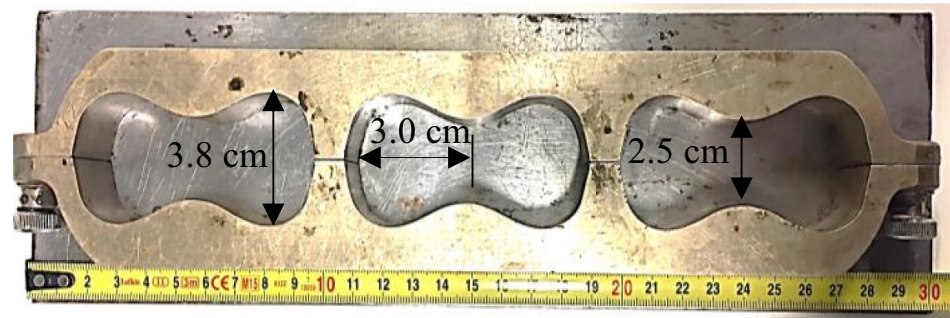

(a) Dog-bone shaped mold

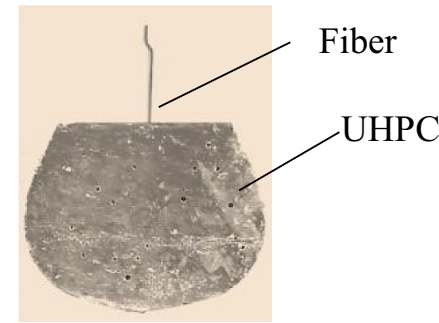

(b) Single fiber in UHPC matrix

Fig. 3. Mold and specimen. 


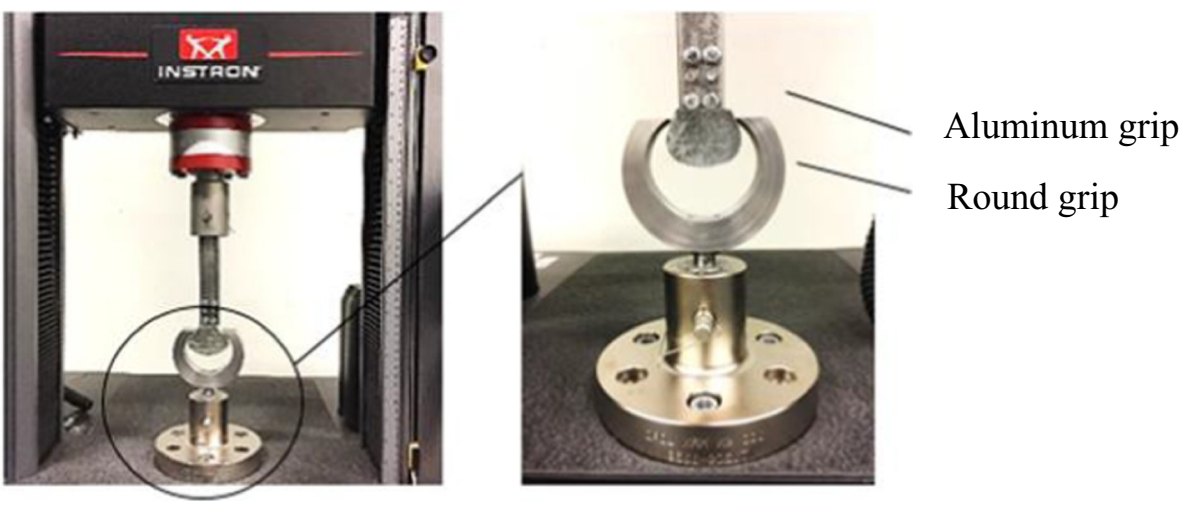

Fig. 4. Pullout test setup.

$\mathrm{DIF}=\beta_{\mathrm{t}}\left(\frac{\dot{\varepsilon}_{\mathrm{t}}}{\dot{\varepsilon}_{\mathrm{t} 0}}\right)^{1 / 3}$ for $\dot{\varepsilon}_{\mathrm{t}}>30 \mathrm{~s}^{-1}$

where $\dot{\varepsilon}_{\mathrm{t}}$ is the tensile strain rate, the static reference rate $\varepsilon_{\mathrm{t} 0}=3 \times 10^{-6} \mathrm{~s}^{-1}$, parameters $\delta=\frac{1}{10+\frac{3 f_{\mathrm{cu}}}{5}}, \log \beta_{\mathrm{t}}=7.112 \delta-2.33$, and $f_{\text {cu }}$ is the static compressive strength (in $\mathrm{MPa}$ ).

\subsection{Mechanisms behind concrete rate dependency}

Concerning the dynamic tension, the enhancement of the tensile strength may be mainly attributed to two factors: (1) the moisture in the pores, i.e. the Stefan effect, and (2) the inertia effect associated with micro-cracking phenomenon $[27,40]$.

\subsubsection{Stefan effect}

The free water in the pores of concrete material is assumed to exhibit the Stefan effect, which can be explained by considering the cohesive force between two plates separated by an incompressible water film. Most researchers consider the Stefan effect to be one of the vital factors contributing to the rate effects [41]. According to Weerheijm et al. [8] and Vegt [42], the amount, dimension and distribution of pores, as well as the saturation degree of the pores in concrete play an important role on the Stefan effect.

\subsubsection{Micro inertia effect}

Inertia at micro-level can affect the stress fields around the material defects and delay the damage initiation of cracks, resulting in an enhancement in the maximum strength [43]. The inertial effects can induce limitations in both crack initiation and propagation at micro-levels. Under static loading, the rate of fracture energy dissipation is in balance with the rate of the external energy supply. At higher loading rates, however, the energy supply rate is too high that the external power cannot be absorbed in the fracture process. Hence, a major part of the supplied external power is stored as kinetic and deformation energies around cracks, changing the stress distribution around crack tips and reducing the stress intensity factor [8]. A smaller stress intensity means fewer energy flux into the fracture zone, which then results in a decrease of the crack develop velocity [43]. As a consequence, the crack propagation is limited and the material strength increases with the loading rate $[8,44]$.

\subsection{Rate dependency of fiber-matrix interface}

As illustrated in the SEM image of the fiber-matrix interface before the pullout tests (Fig. 5a), the interfacial zone between the steel fiber and the UHPC matrix has a relatively larger amount of pores than the matrix itself. Considering that the Stefan effect is associated with the amount and saturation degree of the pores in the concrete matrix $[8,42]$, the influences of the strain rate due to the Stefan effect should be more obvious for the concrete containing more pores and a higher internal humidity. One example is that the tensile strength DIF tend to be higher for the concrete with a lower strength, which usually has higher porosity [45,46]. In addition, the fiber-matrix interface is usually the weakest section in UHPFRC and has a higher potential to crack more seriously than the matrix itself, hence, the micro-inertia effect associated with cracking would be more significant. Consequently, the fiber-matrix interface is expected to have a more prominent rate sensitivity than the UHPC matrix itself, i.e. the DIF of the pullout load can be larger compared to the UHPC tensile strength DIF.

Moreover, when a hooked-end steel fiber is pulled from the UHPC matrix, stress localization will be induced in the matrix surrounding the hooked-end, thereafter micro-cracking will be generated if the localized stresses exceed the matrix tensile strength. Further, the amount of cracks is associated with the level of the matrix confinement, therefore the fiber embedded length [19]. During the pullout process, microcracking continuously initiates along the fiber tunnel and then further propagates in the UHPC matrix. Some micro-cracks are visually observed in the SEM image of the fiber-matrix tunnel after the pullout test at $1000 \mathrm{~mm} / \mathrm{min}$ (Fig. 5b). Since the micro inertial effects on both the crack initiation and propagation contribute to the rate sensitivity of cementitious materials [8], the occurrence and development of these micro-cracks may result in the rate dependency of the fiber-matrix bond. Furthermore, the amount of the rate sensitivity is expected to be associated with the matrix strength, fiber geometry and embedment length, which influence the micro-cracking process [19].

It is worth mentioning that in the single fiber pullout experiments presented in this study, all samples have the same recipe and curing condition, and all of them are tested under a surface-dry condition. Thus, the pore structures and the moisture content in the fiber-matrix interface are assumed to be similar for all the tested samples. Consequently, the rate effects caused by the Stefan effect are presumed to contribute similarly in this study, and more attentions are paid to the contribution of the micro inertial effects when analyzing the rate-dependent pullout behaviors.

\section{Fiber pullout test results}

\subsection{Rate-dependent pullout performances}

The Pullout load-slip relationships for the hooked-end steel fiber with an embedded length $l_{\mathrm{e}}=15 \mathrm{~mm}$ at different loading rates are plotted in Fig. 6. Each data point is the averaged result of at least five tests. To analyze the rate dependency of the pullout performance, the pullout process is divided into the following stages [32]:

- Stage O-A: The response of the curve is almost linear until the initiation of fiber-matrix debonding (Point A). Sequentially, the slope of the pullout load-slip curves varies, indicating the end of the linear 


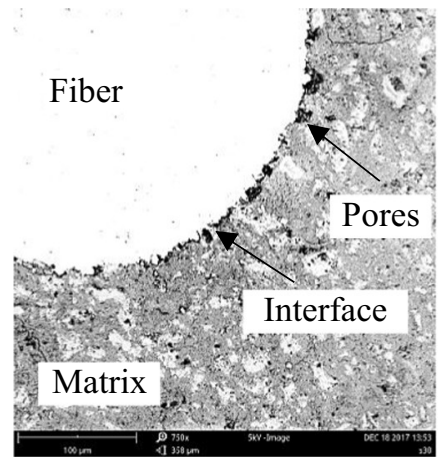

(a) Interface before pullout

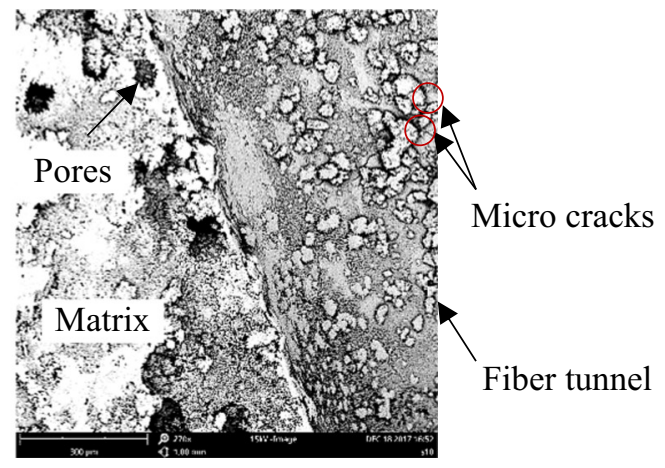

(b) Interface after pullout

Fig. 5. SEM images of microstructures in fiber-matrix interface.

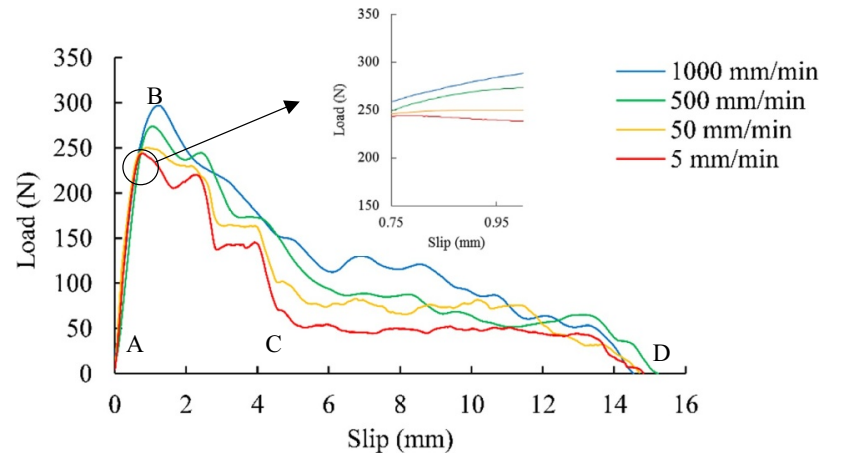

Fig. 6. Pullout performances at different loading rates $\left(l_{\mathrm{e}}=15 \mathrm{~mm}\right)$.

elastic behavior.

- Stage A-B: The debonding process continues with the increase of the pullout load. After the complete debonding of the fiber, the contribution of the hook is activated. Through this stage, the fiber hook undergoes large deformations, i.e. plastic hinges are formed in the two curved sections of the hook due to the occurrence of the plastic bending. The pullout load achieves its peak at Point B.

- Stage B-C: In the post-peak stage, the fiber hook experiences a straightening procedure, during which both the plastic hinges and the fiber-matrix interfacial friction play a role. The peaks and drops of the curves after Point B are associated with the deformations of the hook, contributing to the enhancement of the pullout load in the post-peak stage.

- Stage C-D: When the hook is fully straightened (Point C), the plastic hinges are deactivated and the interfacial friction becomes the dominant mechanism. The pullout load decreases gradually due to the reduction of the remaining embedded length until the fiber is completely pulled out (Point D).

The curves in Fig. 6 at different loading rates confirm the rate sensitivity of the pullout performance. Insignificant rate effects are observed in the initial elastic Stage O-A since the strain rates have negligible effects on the elastic modules of steel and concrete in tension [47]. On the contrary, Stage A-B exhibits a rate sensitivity that the slope of the curve increases slightly with the increase of the rate. The peak pullout load and corresponding slip at Point B are significantly enhanced at higher loading rates and the fluctuations of the curves at Stage B-C become less obvious. Moreover, the slip range of Stage B-C expands while that of Stage C-D narrows with the increase of the loading rate.

Since the pullout performance in Stage C-D is primarily dependent on the fiber-matrix friction, it can be inferred that the frictional force is rate dependent, which is in line with the findings in refs. [19,20].
However, this trend differs with the observation in ref. [48] which investigated the pullout behavior of a normal concrete. In that study, the descend part of the pullout load-slip curve is found to be insensitive to the loading rate, leading to the conclusion that the frictional force is not rate dependent. The rate dependent behavior in Stage C-D may be attributed to the stronger bond between the fiber and the UHPC matrix. More efforts are needed to debond the fiber from the UHPC than from the conventional concrete, and the pullout process may induce more micro-cracks in the matrix, the initiation and propagation of which in turn amplify the rate effects. In addition, comparisons of the curves at Stage B-C suggest that the mechanical anchorage due to the hooked-end is also rate sensitive. The peaks and drops at Stage B-C due to the anchorage become less obvious at higher loading rates, indicating a less significant contribution of the hook under dynamic conditions.

\subsection{Rate effects on the pullout load and energy}

Fig. 7 plots the influences of loading strain rate on the peak pullout load and energy in the case of $l_{\mathrm{e}}=15 \mathrm{~mm}$. The energy dissipation is defined geometrically by the area below the pullout load-slip curve (Fig. 6). The points illustrated in the figures are the averaged results of each group and the error bars indicate the min and max values. As shown in Fig. 7a, the peak load increases from $244.1 \mathrm{~N}$ at the loading rate $5 \mathrm{~mm} / \mathrm{min}$ to $297.1 \mathrm{~N}$ at $1000 \mathrm{~mm} / \mathrm{min}$. The pullout energy undergoes a similar trend, increasing from $1301.3 \mathrm{~N} \cdot \mathrm{m}$ to $1901.3 \mathrm{~N} \cdot \mathrm{m}$ at the corresponding loading rates. For both the peak pullout load and the energy, more apparent improvements are observed in the intermediate loading rate range than in the quasi-static one. For example, the pullout load has a $2.5 \%$ enhancement when the loading rate increases from $5 \mathrm{~mm} / \mathrm{min}$ to $50 \mathrm{~mm} / \mathrm{min}$ (a fold of ten), while the enhancement is $8.5 \%$ when the rate changes from $500 \mathrm{~mm} / \mathrm{min}$ to $1000 \mathrm{~mm} / \mathrm{min}$ (a fold of two). Additionally, it should be pointed out that scattering of experimental results is observed at the four tested rates, as shown by the error bars in Fig. 7a. The maximum scatterings of both the pullout load and the energy occur at $1000 \mathrm{~mm} / \mathrm{min}$, the variation coefficients of which reach $16 \%$ and $22 \%$, respectively. A similar trend was reported in ref. [49] which studied the dynamic pullout behavior of PE fibers, and it is suggested that the higher variation at higher loading rates may be due to the larger scatterings of the matrix properties at higher rates [49].

The relationships between the strain rates and DIFs of the peak pullout load and the energy are summarized in Fig. 7b, where the averaged results are given. The DIFs for the peak pullout load at $50 \mathrm{~mm} / \mathrm{min}, 500 \mathrm{~mm} / \mathrm{min}$ and $1000 \mathrm{~mm} / \mathrm{min}$ are $1.03,1.12$ and 1.22 , while the corresponding values for the pullout energy are 1.17, 1.28 and 1.46, respectively. These strong rate dependencies were also observed in a previous research [18], which analyzed the dynamic pullout responses of the same hooked-end steel fiber with $l_{\mathrm{e}}=12.7 \mathrm{~mm}$ 


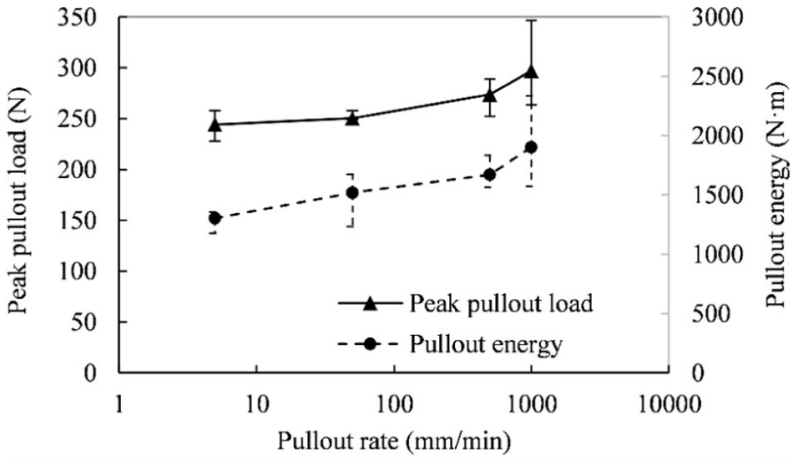

(a) Load and energy

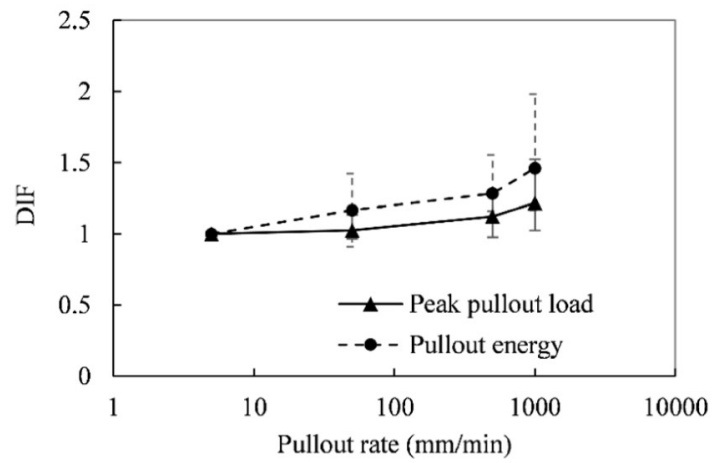

(b) DIFs

Fig. 7. Rate effects on the peak pullout load and energy $\left(l_{\mathrm{e}}=15 \mathrm{~mm}\right)$.

embedded in a very high strength concrete of $f_{\mathrm{c}}=175 \mathrm{MPa}$. The DIFs of the peak pullout load and the energy at loading rate $1524 \mathrm{~mm} / \mathrm{min}$ in their study were 1.28 and 1.49 , which are close to the values at $1000 \mathrm{~mm} / \mathrm{min}$ in the present study, i.e. 1.22 and 1.46 . It should be noted that [18] only investigated the pullout performances at loading rate $1.26 \mathrm{~mm} / \mathrm{min}$ and $1524 \mathrm{~mm} / \mathrm{min}$ and the former was taken as the static rate when calculating the DIFs.

At the tested loading rates, the pullout energy tends to be more rate sensitive than the peak pullout load, i.e. the DIF of the pullout energy is always larger than that of the peak pullout load. This is in line with the findings in Xu et al. [19] which studied the pullout behaviors of halfhook fibers, although the causes were not addressed in their study. The more obvious rate effects on the pullout energy may be correlated to the additional micro-cracking and the additional resistance due to the micro-inertia effects [8]. Furthermore, the debonding process at the early pullout stages and the hook deformations at the fiber end generate micro cracks in the matrix; and the inertia effects of this micro-cracking contribute to the rate dependency of the peak pullout load. On the other hand, with the slippery of the fiber at the later stages of the pullout process, some UHPC matrix particles adhere to the fiber surface [32], causing more damage to the surrounding matrix and accelerating the cracks developments. In the case of the pullout energy, micro inertia effects result from both the fiber debonding and the slippery during the whole pullout process have effects, hence rate effects on the pullout energy are enhanced.

Furthermore, the DIFs of the pullout behavior are higher comparing to those of the UHPC/UHPFRC tensile strength and toughness. For example, the dynamic performances of a UHPFRC matrix reinforced with $2 \%$ straight steel fibers were investigated in refs. [50,51], which reported that the DIFs of the UHPFRC tensile strength and fracture energy at the strain rate of $0.1 \mathrm{~s}^{-1}$ (around $450 \mathrm{~mm} / \mathrm{min}$ ) were 1.04 and 1.15 , respectively. In comparison, the DIFs of the pullout load and energy in this study are 1.12 and 1.28 at the similar loading rate, which are higher than the DIFs of the UHPFRC material. Ranade et al. [49]

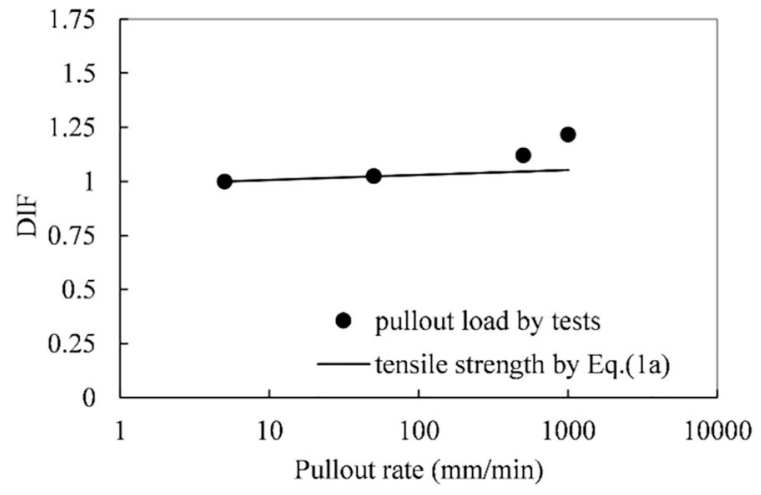

Fig. 8. DIFs of pullout load and UHPC tensile strength.

analyzed the rate effects on a high strength-high ductility concrete matrix (with a similar compressive strength as the UHPC), and the DIF of the fracture toughness at $600 \mathrm{~mm} / \mathrm{min}$ was 1.19 , which is also smaller than that of the pullout energy in this study. Since experimental studies concerning the DIFs of UHPC/UHPFRC at intermediate strain rates are very limited in the available literature, the DIFs of concrete tensile strength calculated by Eq. (1a) are also adopted for further comparisons (see Fig. 8). It is shown that the pullout load DIF at a low loading rate, e.g. $50 \mathrm{~mm} / \mathrm{min}$, is similar to the corresponding DIF of the UHPC tensile strength, whereas at intermediate strain rates the pullout load is more rate sensitive than the matrix tensile strength. These higher DIFs of the pullout behavior may be attributed to the more porous interface between the fiber and the matrix as well as its relatively lower strength than the matrix itself. As mentioned in Section 3.3, the Stefan effect is more prominent on the concrete containing more pores, and the micro inertia effect plays a more crucial role on the weaker matrix that is more susceptible to cracking. These, therefore, result in the higher DIFs of the pullout load and energy.

\subsection{Rate effects on the maximum and equivalent bond strength}

To provide a quantitative evaluation of the rate effects on the fibermatrix interfacial bond properties, the maximum bond strength and equivalent bond strength are calculated. The maximum bond strength $\tau_{\max }$ is calculated based on the peak pullout load $P_{\max }$, and it is closely associated to the maximum tensile strength of the fiber reinforced composite [52]. The equivalent bond strength $\tau_{\text {eq }}$ is defined as the average bond strength based on the dissipated pullout energy $E$ during the entire fiber pullout process, which is related to the cracking behavior of the material $[19,52]$. Equations for calculating the two parameters are given below:

$\tau_{\max }=\frac{P_{\max }}{\pi d L}$

$\tau_{\mathrm{eq}}=\frac{2 E}{\pi d L^{2}}$

where $d$ is the diameter of the fiber and $L$ is the actual fiber embedded length obtained from the pullout load-slip curves.

Fig. 9 plots the influences of the strain rate on the maximum and equivalent bond strength with $l_{\mathrm{e}}=15 \mathrm{~mm}$. At the quasi-static loading rate $(5 \mathrm{~mm} / \mathrm{min})$, the maximum and equivalent bond strength are 14.0 MPa and 10.1 MPa, respectively. While at the intermediate loading rate of $500 \mathrm{~mm} / \mathrm{min}$, the values increase to $15.3 \mathrm{MPa}$ and $12.2 \mathrm{MPa}$, i.e. $9.1 \%$ and $21.5 \%$ enhancements, respectively. With the further increase of the loading rate, the maximum and equivalent bond strength at $1000 \mathrm{~mm} / \mathrm{min}$ experience noticeable growths, i.e. the values reach to 17.3 MPa and 15.3 MPa, respectively. As depicted in Fig. 9b, DIFs of the equivalent bond strength are higher than those of the maximum bond strength at the tested loading rates, indicating a more obvious rate 


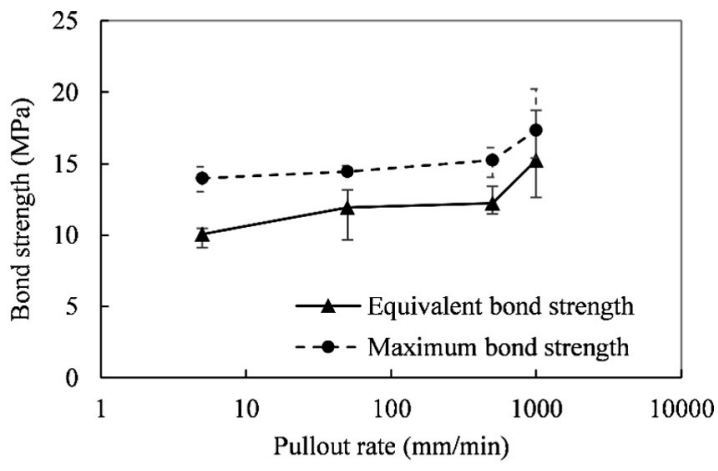

(a) Bond strength

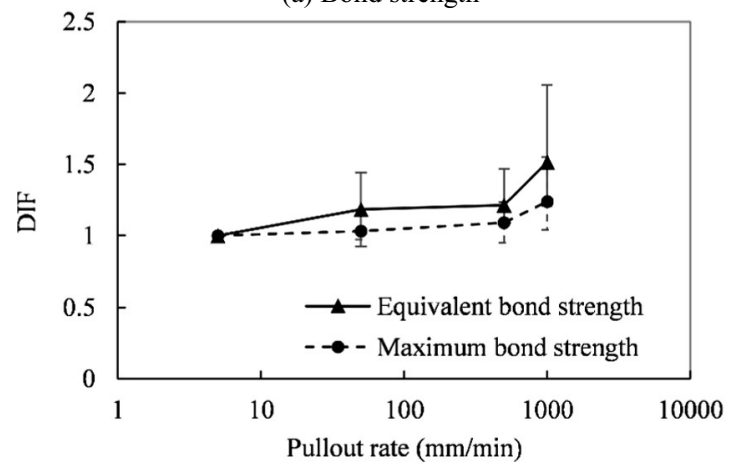

(b) DIFs

Fig. 9. Rate effects on the bond strength $\left(l_{\mathrm{e}}=15 \mathrm{~mm}\right)$.

sensitivity of the former. For instance, the DIFs for the maximum bond strength at $50 \mathrm{~mm} / \mathrm{min}, 500 \mathrm{~mm} / \mathrm{min}$ and $1000 \mathrm{~mm} / \mathrm{min}$ are $1.03,1.09$ and 1.24 , respectively; whereas the corresponding values for the equivalent bond strength are $1.18,1.21$ and 1.52 , which are approximately $14.6 \%, 11.0 \%$ and $22.6 \%$ higher, respectively.

\subsection{Effects of embedded length on rate dependency}

To investigate the effects of fiber embedded length on the rate dependency of the hooked-end fiber pullout performance, a series of single fiber pullout tests are conducted with a smaller embedded length $l_{\mathrm{e}}=10 \mathrm{~mm}$. Fig. 10 illustrates the pullout load-slip curves at various loading rates with $l_{\mathrm{e}}=10 \mathrm{~mm}$, in which similar trend can be observed as shown in Fig. $6\left(l_{\mathrm{e}}=15 \mathrm{~mm}\right)$.

Comparisons of the test results between the $l_{\mathrm{e}}=10 \mathrm{~mm}$ and $15 \mathrm{~mm}$ categories are plotted in Fig. 11. As depicted in the figures, the peak pullout load and the pullout energy are enhanced with the increase of the embedded length at the tested loading rates. For example, the peak pullout load and the energy at $1000 \mathrm{~mm} / \mathrm{min}$ are $26.5 \%$ and $88.8 \%$

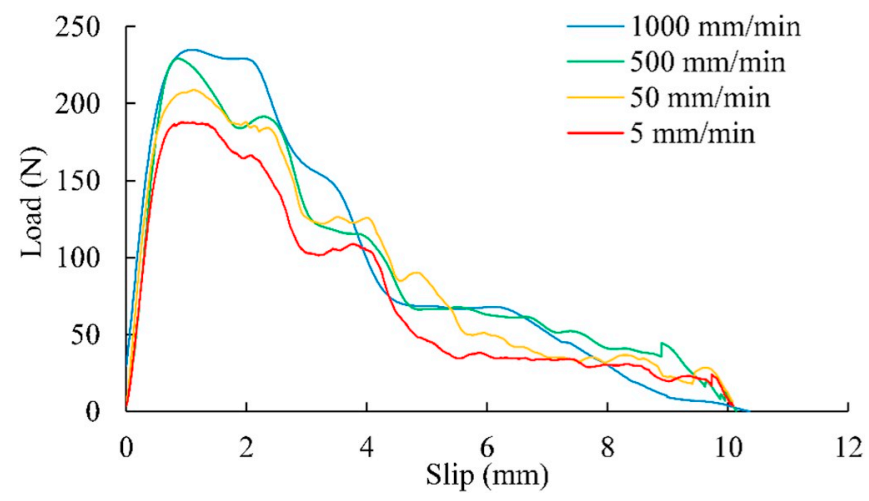

Fig. 10. Pullout load-slip curves at different loading rates $\left(l_{\mathrm{e}}=10 \mathrm{~mm}\right)$. higher for the $l_{\mathrm{e}}=15 \mathrm{~mm}$ category than for its counterpart with $l_{\mathrm{e}}=10 \mathrm{~mm}$. In contrast, the maximum and equivalent bond strength tend to be smaller for a larger embedded length, e.g. the maximum bond strength at $500 \mathrm{~mm} / \mathrm{min}$ for the $l_{\mathrm{e}}=10 \mathrm{~mm}$ and $15 \mathrm{~mm}$ categories are 19.2 MPa and 15.3 MPa, respectively. These observations are consistent with that in refs. [15,32], which analyzed the influence of the embedded length under static loadings. The higher equivalent and maximum bond strength with a smaller embedded length might be due to the more remarkable contribution of the hooked-end than the straight part of the fiber, despite of the external loading rates. Moreover, the influence of the embedded length is the most obvious on the pullout energy, indicating a prominent influence of the fiber length on the energy absorption capacity of UHPFRC composites.

The effects of the embedded length on the DIFs of the peak pullout load, pullout energy, and maximum and equivalent bond strength are depicted in Fig. 12. It is obvious that the DIFs increase with the increase of the loading rate for the two tested embedded lengths. Moreover, the DIFs of the peak pullout load and the maximum bond strength are higher for the smaller embedded length category. For instance, the DIFs of the peak pullout load and the maximum bond strength at $500 \mathrm{~mm} /$ min are 1.12 and 1.09 for the $l_{\mathrm{e}}=15 \mathrm{~mm}$ category, while those for the $l_{\mathrm{e}}=10 \mathrm{~mm}$ category increase to 1.22 and 1.21 , respectively. One possible reason attributing to this trend is the micro-cracking process in the UHPC matrix associated with the matrix confinement (Fig. 13) [19]. At the initial stage of the pullout process, local pressure is induced into the surrounding matrix near the hooked-end, generating micro splitting cracks in the hook bending points where stresses are localized. With a larger embedded length, the matrix confinement is higher, which offsets the split cracking and thus reduces the rate effects [19]. While with a smaller embedded length, micro-cracks can occur both in plane and out of plane because of the reduced confinement, contributing to a more apparent rate effects [19]. Since the maximum bond strength depends on the peak pullout load, and the latter is associated with the confinement-dependent micro-cracking process at Stage A-B, the rate effects on the maximum bond strength and the peak pullout load are thus more evident with a smaller embedded length, i.e. $l_{\mathrm{e}}=10 \mathrm{~mm}$. On the other hand, the rate dependencies of the pullout energy and the equivalent bond strength are related to the micro-cracking initiation and propagation at the whole pullout stages $\mathrm{A}$ to $\mathrm{D}$, and the rate effects induced in the later fiber slippery process have more influences on fibers with longer embedded lengths. Therefore, DIFs of the pullout energy and the equivalent bond strength are slightly higher for the $l_{\mathrm{e}}=15 \mathrm{~mm}$ category, especially at an intermediate loading rate, e.g. $1000 \mathrm{~mm} / \mathrm{min}$, at which the contribution of the hook is less prominent (see Section 4.1).

Furthermore, since the UHPC matrix usually has a very high compressive strength, the matrix confinement in a UHPFRC tends to be more prominent than that in a normal concrete. Hence, the embedded length, i.e. fiber length, becomes a significant influencing factor on the rate effects of UHPFRC and should be taken into consideration when designing impact-resistant UHPFRC structures. In addition, the observation that the peak pullout load is more rate sensitive with a smaller embedded length while the pullout energy has an opposite trend also gives guides for the design of UHPFRC. For instance, for UHPFRC constructed in earthquake zones, the energy absorbing capacity may be more important than the composite strength, thus longer hooked-end steel fibers are preferred for these structures since more pullout energy would be consumed during earthquakes. In contrast, for structures whose dynamic strength is a more vital factor, incorporating shorter fibers may generate more advantages considering the higher enhancement of its load carrying ability at dynamic rates.

\section{Rate-dependent model for predicting the dynamic peak pullout} load

A practical model was proposed by Zile and Zile [30], which can be 


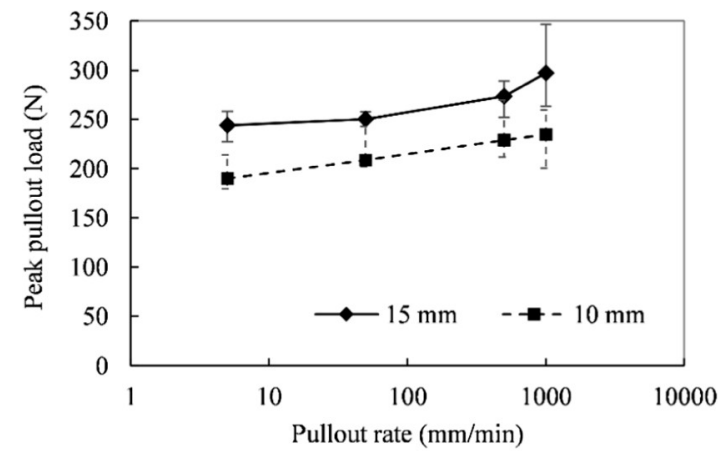

(a) Peak pullout load

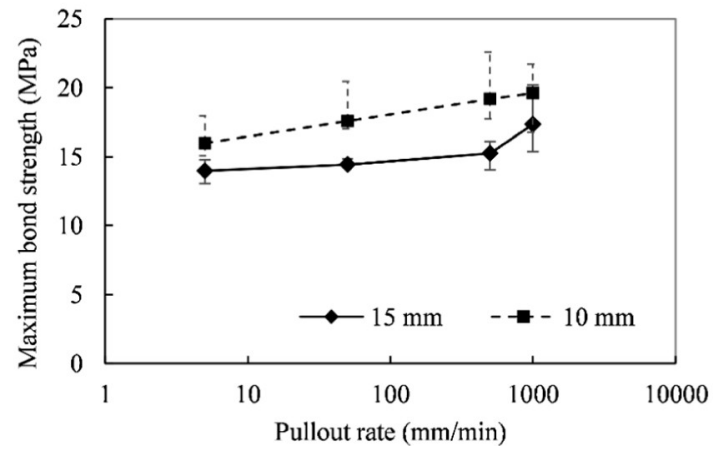

(c) Maximum bond strength

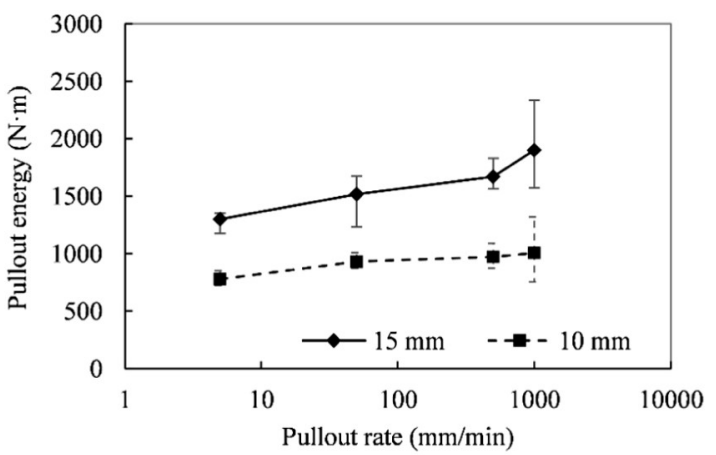

(b) Pullout energy

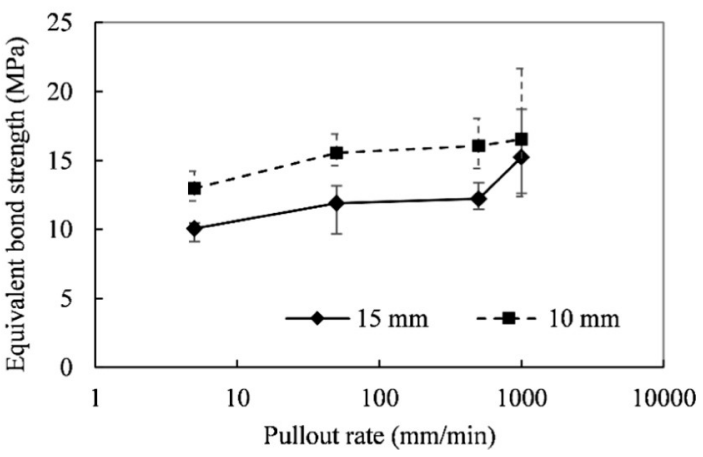

(d) Equivalent bond strength

Fig. 11. Effects of embedded lengths on test results.

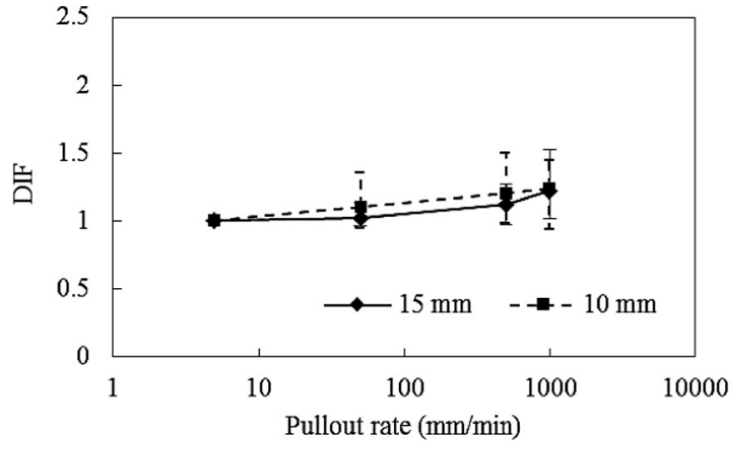

(a) Peak pullout load

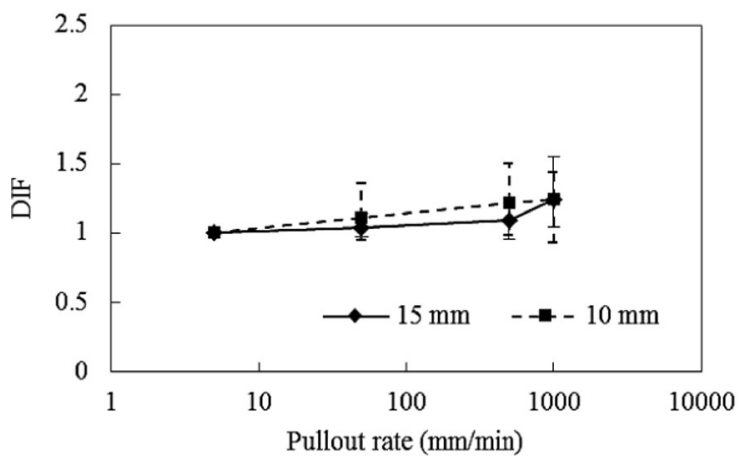

(c) Maximum bond strength

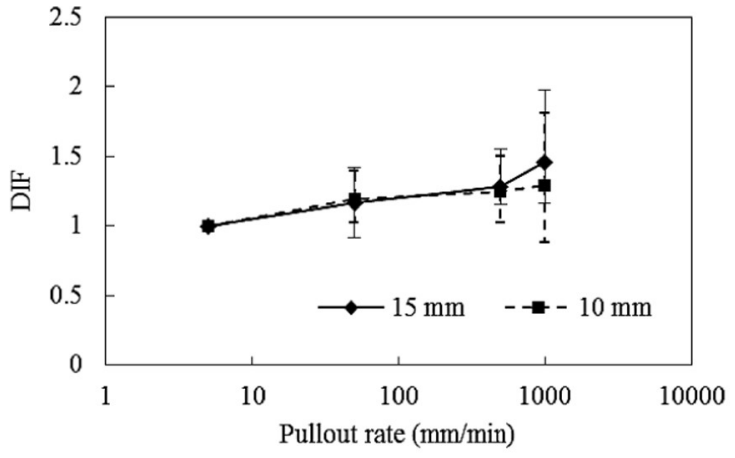

(b) Pullout energy

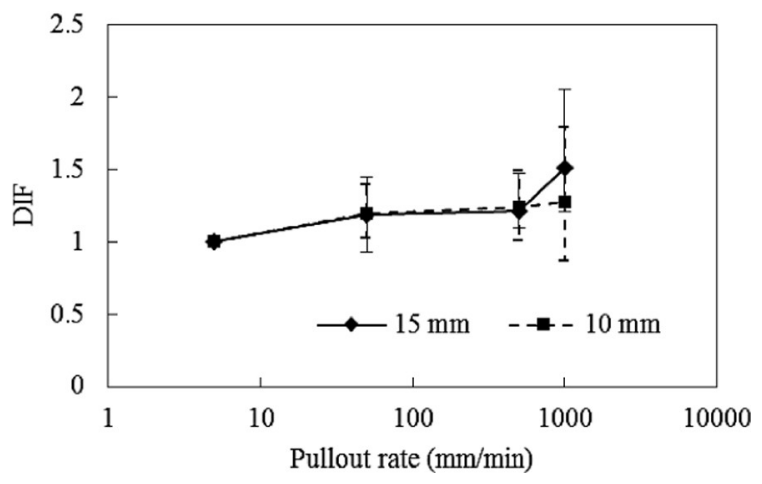

(d) Equivalent bond strength

Fig. 12. Effects of embedded lengths on DIFs. 


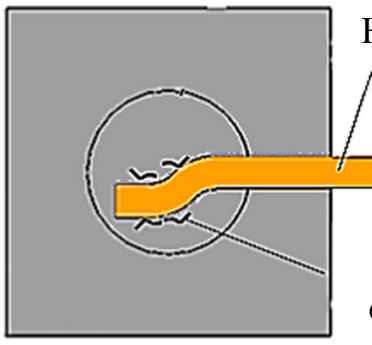

Hooked-end fiber
Potential cracking
caused by the hook

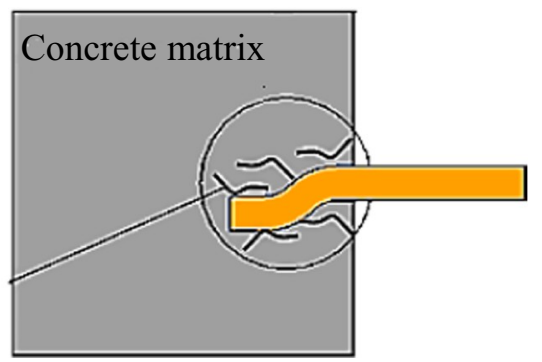

(a) Larger embedded length

(b) Smaller embedded length

Fig. 13. Influence of embedded length (confinement is higher with a larger embedded length, which reduces cracking).

used to predict the peak pullout load under quasi-static loading. In the present study, a new rate-dependent model for dynamic loading rates ranging from quasi-static to intermediate levels is developed using this model as a base.

First of all, the peak pullout load $P_{\max }$ is split into two components, i.e. the anchorage part due to the hooked-end $P_{\mathrm{h}}$ and the friction part due to the frictional bond between the fiber and the matrix $P_{\mathrm{f}}$ :

$P_{\max }=P_{\mathrm{h}}+P_{\mathrm{f}}$

According to the pulley model in ref. [27], the pullout load caused by the mechanical anchorage of the hooked-end can be modelled as a fiber passing through two curved ducts (Fig. 14a). The anchorage load is given as $[27,30]$ :

$P_{\mathrm{h}}=\frac{\pi d^{2} \sigma_{\mathrm{y}}}{12 \cos \alpha(1-\mu \cos \beta)}\left(1+\frac{\mu \cos \beta}{1-\mu \cos \beta}\right)=\frac{\pi d^{2} \sigma_{\mathrm{y}}}{12(1-\mu \cos \beta)^{2} \cos \alpha}$

where $d$ and $\sigma_{\mathrm{y}}$ are the diameter and yield strength of the hooked-end steel fiber, respectively; $\alpha$ and $\beta$ are related to the hook geometry, as shown in Fig. 13a: $\alpha$ is the hook angle, and $\beta$ is the angle between the directions of the pullout force $P$ and the reaction force $R$ at the pulley center. $\mu$ is the friction coefficient following:

$\mu=\mu_{0}+\frac{\tau}{\tau_{0}}$

in which the empirical parameters are given as $\mu_{0}=0.08$, $\tau_{0}=21.28 \mathrm{MPa}[30,53] . \tau$ is the frictional shear stress during the fiber slippery stage, the value of which can be obtained from the straight fiber pullout tests or approximately estimated with the pullout load at Stage C-D since in this stage the fiber-matrix friction is the main factor affecting the pullout load. Depending on the state of the pullout load, i.e. $P_{\mathrm{CD}}$ corresponds to a quasi-static or a dynamic load, $\tau$ can be regraded to a quasi-static frictional shear stress $\tau_{\mathrm{s}}$ or a dynamic one $\tau_{\mathrm{d}}$. Consequently, $\mu$ can be a static or a dynamic friction coefficient. The expression of $\tau$ is given as:

$\tau=\frac{P_{C D}}{\pi d\left(l_{\mathrm{e}}-S_{\mathrm{C}}\right)}$

in which $P_{\mathrm{CD}}$ is the average pullout load at Stage C-D and $S_{\mathrm{C}}$ is the slip of the fiber when Stage C-D starts.

The friction part $P_{\mathrm{f}}$ is calculated by:

$P_{\mathrm{f}}=\pi d \tau\left(l_{I, I I}+l_{I I, I I I}+l_{I I I, I V}\right)$

where $l_{I, I I}$ and $l_{I I, I I}$ are the lengths depending on the hook geometry (Fig. 14b); $l_{I I I, I V}$ is the length of the embeded part of the fiber without the hook:

$l_{I I I, I V}=l_{e}-l_{I, I I}-l_{I I, I I} \sin \alpha$

Substituting Eqs. (5), (6) and (8) into Eq. (4) yields:

$P_{\max }=\frac{\pi d^{2} \sigma_{\mathrm{y}}}{12\left[1-\left(\mu_{0}+\frac{\tau}{\tau_{0}}\right) \cos \beta\right]^{2} \cos \alpha}+\pi d \tau\left(l_{I, I I}+l_{I I, I I I}+l_{I I I, I V}\right)$

Under dynamic loadings, the dynamic frictional shear stress $\tau_{\mathrm{d}}$ is rate dependent and the rate dependency varies with the embedded length, as discussed in Section 4.4. Following the expression of the concrete tensile strength DIF in Eqs. (1a), (1b), an empirical equation to account the rate effects on the frictional shear stress at dynamic loading rates up to the intermediate level is given as:

$\frac{\tau_{\mathrm{d}}}{\tau_{\mathrm{s}}}=\left(\frac{\dot{\varepsilon}_{\mathrm{d}}}{\dot{\varepsilon}_{\mathrm{s}}}\right)^{\varphi}$

where $\tau_{\mathrm{s}}$ and $\tau_{\mathrm{d}}$ are the frictional shear stresses under quasi-static and dynamic loading, respectively. $\dot{\varepsilon_{\mathrm{s}}}$ is the quasi-static reference rate and $\varepsilon_{\mathrm{d}}$ is the dynamic loading strain rate. $\varphi$ is an empirical parameter which has a similar expression as the parameter $\delta$ in Eqs. (1a), (1b). Applying nonlinear regression analysis of the experimental results in this study, $\varphi$ is obtained as:

$\varphi=\mathrm{e}^{0.16 l_{e}} /\left(5+0.6 f_{\mathrm{cu}}\right)$

where the embedded length $l_{e}$ is in mm and the matrix strength $f_{\mathrm{cu}}$ is in MPa.

Combining Eqs. (10) and (11) results in the predicting formula for the dynamic peak pullout load of the hooked-end steel fiber embedded in the UHPC matrix:

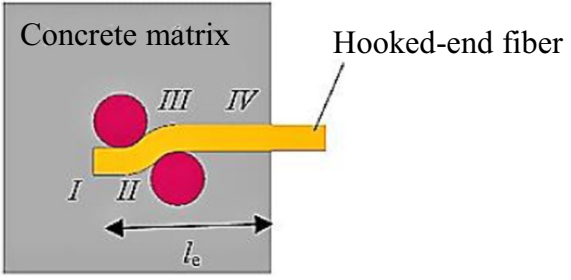

(b) Fiber geometry

(a) Frictional pulley model [30]

Fig. 14. Hooked-end fiber pullout. 
Table 2

Peak pullout loads from experiments and prediction model.

\begin{tabular}{ccccc}
\hline $\begin{array}{l}\text { Embedded } \\
\text { length (mm) }\end{array}$ & $\begin{array}{l}\text { Loading rate } \\
(\mathrm{mm} / \mathrm{min})\end{array}$ & $\begin{array}{l}\text { Averaged } \\
\text { experimental } \\
\text { results (N) }\end{array}$ & $\begin{array}{l}\text { Model } \\
\text { prediction } \\
\text { results (N) }\end{array}$ & Error (\%) \\
\hline \multirow{2}{*}{15} & 5 & 244.1 & 229.2 & 6.1 \\
& 50 & 250.3 & 255.1 & 1.9 \\
& 500 & 273.8 & 289.2 & 5.6 \\
10 & 1000 & 297.1 & 301.5 & 1.5 \\
& 5 & 190.1 & 208.6 & 9.7 \\
& 50 & 209.0 & 216.8 & 3.7 \\
$12.7[18]$ & 500 & 229.2 & 226.1 & 1.3 \\
& 1000 & 234.9 & 229.2 & 2.5 \\
$6.35[18]$ & 1.26 & 188.1 & 201.0 & 4.6 \\
& 1.26 & 211.9 & 212.7 & 6.8 \\
& 1500 & 164.7 & 172.2 & 6.8 \\
& 185.1 & 174.1 & 4.0 \\
\hline
\end{tabular}

$$
\begin{aligned}
P_{\max }= & \frac{\pi d^{2} \sigma_{\mathrm{y}}}{12\left[1-\left(\mu_{0}+\frac{\tau_{\mathrm{s}}}{\tau_{0}}\left(\frac{\dot{\varepsilon}_{\mathrm{d}}}{\dot{\mathrm{s}}_{\mathrm{s}}}\right)^{\varphi}\right) \cos \beta\right]^{2} \cos \alpha} \\
& +\pi d \tau_{\mathrm{s}}\left(\frac{\dot{\varepsilon}_{\mathrm{d}}}{\dot{\varepsilon}_{\mathrm{s}}}\right)^{\varphi}\left(l_{I, I I}+l_{I I, I I I}+l_{I I I, I V}\right)
\end{aligned}
$$

Definitions of all parameters in Eq. (13) have been given in the above description. With a given experiment condition, parameters corresponding to the concrete strength, fiber properties and embedded length are known, then the dynamic peak pullout loads $P_{\max }$ under various pullout rates $\varepsilon_{\mathrm{d}}$ can be predicted using Eq. (13).

To validate the above prediction model, experimental results from this study and [18] are applied. The hooked-end steel fiber used in the two researches are the same, and the fiber geometry related parameters adopted in the prediction model are $\alpha=45^{\circ}, \beta=67.5^{\circ}, l_{I, I I}=2.5 \mathrm{~mm}$, $l_{I I, I I I}=2.12 \mathrm{~mm}$ and $d=0.375 \mathrm{~mm}$. The compressive strength of the concrete matrix in this study and [18] are $156 \mathrm{MPa}$ and $175 \mathrm{MPa}$, respectively. The quasi-static frictional shear stresses $\tau_{\mathrm{s}}$ for the two studies are taken as 3.5 MPa and 4 MPa based on the quasi-static pullout loadslip curves.

Comparisons between the experimental and the predicted peak pullout loads are illustrated in Table 2 and Fig. 15, in which variations of the experimental data in this study are also denoted by the error bars (note that variations of the results in ref. [18] are not clear due to the lack of data). Regarding such scattering, the predictions of the dynamic pullout load by the developed model always fall within the range of experimental results. These reasonably good correlations confirm the validity of the proposed prediction model, especially at higher loading rates.

At the quasi-static loading rate, Eq. (13) yields identical results as the model developed in ref. [30]. Corresponding values in Table 2 show that the accuracy of the model is slightly lower under the quasi-static condition compared with those at higher loading rates. This may be due to the fact that some empirical parameters in the quasi-static model in ref. [30], e.g. $\tau_{0}$ and $\mu_{0}$, are determined based on normal strength concrete rather than on UHPFRC. More investigations are needed in order to improve the accuracy of the quasi-static model. Nevertheless, considering that the presented errors are acceptable, the same $\tau_{0}$ and $\mu_{0}$ are applied in this model as those in refs. [30,53]. In addition, it should be noted that the values for $\tau_{0}$ and $\mu_{0}$ are suggested by Geng and Leung [53] using extensive experiments under quasi-static loadings; however, the value of $\tau_{0}$ may be different under dynamic loadings. By assuming that its rate dependency could also be expressed in a similar format as Eq. (11), the presented model accounts the rate sensitivity of $\tau_{0}$ together with that of $\tau_{\mathrm{d}}$ in the parameter $\varphi$. Furthermore, as indicated by Eq. (6), $\mu_{0}$ represents the intercept value of the friction coefficient when $\tau=0$, which therefore expected to remain constant under both quasi-static and dynamic loadings, i.e. without rate sensitivity. The good agreements in Fig. 15 and Table 2 confirm the rationality of the above hypothesis.

\section{Conclusions}

This study investigates the rate-dependent pullout performances of the hooked-end steel fiber embedded in the UHPC matrix at loading rates from $5 \mathrm{~mm} / \mathrm{min}$ to $1000 \mathrm{~mm} / \mathrm{min}$. The rate sensitivity of the dynamic fiber pullout responses and the related mechanisms are analyzed. An analytical model to predict the dynamic peak pullout load covering loading rates from quasi-static to intermediate levels is proposed and validated. The following conclusions can be drawn from the study:

(1) The pullout performance of the hooked-end steel fiber embedded in the UHPC matrix is rate dependent, and the loading rate affects both the mechanical anchorage and the interfacial friction during the pullout process.

(2) The pullout energy is more rate sensitive than the peak pullout load. With an embedded length of $15 \mathrm{~mm}$, the DIFs for the pullout energy at $50 \mathrm{~mm} / \mathrm{min}, 500 \mathrm{~mm} / \mathrm{min}$ and $1000 \mathrm{~mm} / \mathrm{min}$ are 1.17 , 1.28 and 1.46, whereas the corresponding values for the peak pullout load are 1.03, 1.12 and 1.22, respectively.

(3) Fiber embedded length affects the rate dependency of the pullout performance. The peak pullout load is more rate sensitive with a smaller embedded length, i.e. $l_{\mathrm{e}}=10 \mathrm{~mm}$. In contrast, the rate dependency of the pullout energy is slightly higher for the $l_{\mathrm{e}}=15 \mathrm{~mm}$ category, especially at intermediate loading rates.

(4) The Stefan effect and the inertia effect due to micro-cracking in the interface are two main mechanisms contribute to the rate effects on the dynamic pullout responses. The more porous and weaker fibermatrix interface has a more prominent rate sensitivity than the

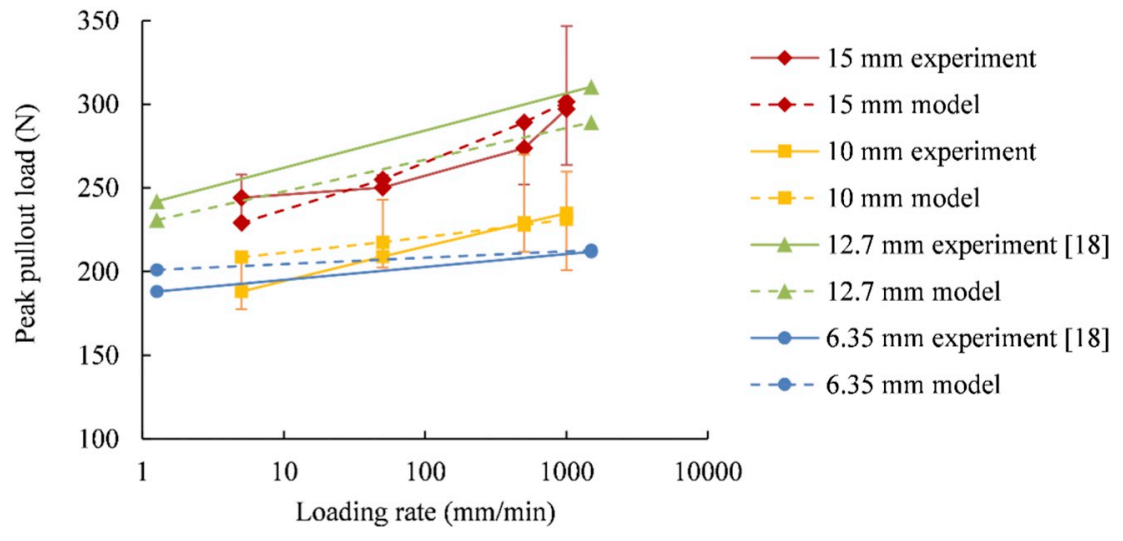

Fig. 15. Prediction model validation. 
UHPC matrix. And the influences of the fiber embedded length are associated with the matrix confinement which affects the interfacial cracking process.

(5) A new analytical model to predict the dynamic peak pullout loads of hooked-end steel fiber at loading rates up to the intermediate level is developed and validated. Influences of the external loading rate, concrete compressive strength, fiber properties and embedded length are accounted in the model.

\section{Acknowledgements}

This research was carried out under the funding of China
Scholarship Council and Eindhoven University of Technology. Furthermore, the authors wish to express their gratitude to the following sponsors of the Building Materials research group at TU Eindhoven: Rijkswaterstaat Grote Projecten en Onderhoud; GranietImport Benelux; Kijlstra Betonmortel; Struyk Verwo; Attero; Enci; Rijkswaterstaat Zee en Delta-District Noord; Van Gansewinkel Minerals; BTE; V.d. Bosch Beton; Selor; GMB; Icopal; BN International; Eltomation, Knuaf Gips; Hess AAC Systems; Kronos; Joma; CRH Europe Sustainable Concrete Centre; Cement \& Beton Centrum; Heros; Inashco; Keim; Sirius International; Boskalis; NNERGY; Millvision; Sappi and Studio Roex (in chronological order of joining).

\section{Appendix A}

A total of 45 specimens are cast for the pullout tests in this study and at least 5 specimens are tested to calculate the averaged curve for each series. Examples of the averaged pullout load-slip curves are given in Figs. A1 and A2. The commercial data analysis software Origin is adopted for the averaging procedure: (1) import the pullout results obtained from the Instron testing machine to Origin and plot the curves of each specimens in the same group; (2) choose the curves and call Analysis-Mathematics- Average Multiple Curves in Origin; (3) set the average scale to be the full X range and apply linear interpolation to average the data at identical slips. Scatterings of the curves are observed in spite of the efforts dedicated for careful specimen preparation and experiment execution. Moreover, the scattering tends to be more prominent at a higher pullout rate, and it is of the same magnitude for both the $l_{\mathrm{e}}=15 \mathrm{~mm}$ and the $10 \mathrm{~mm}$ categories.

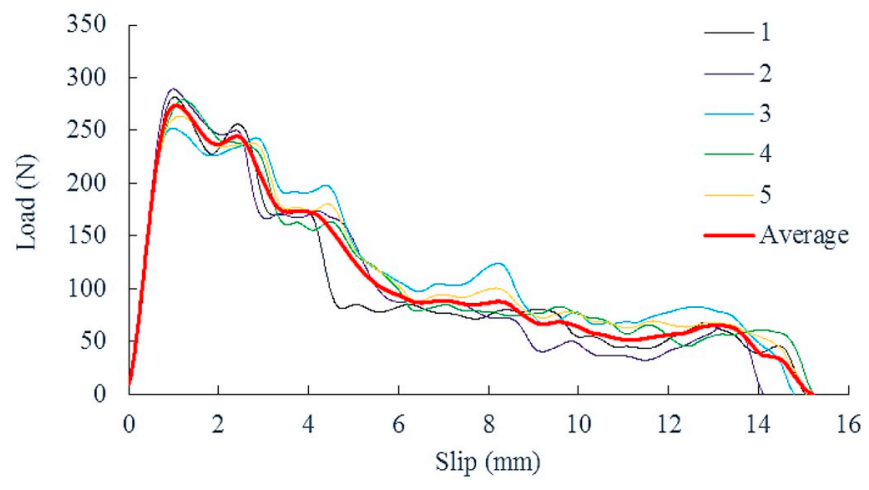

Fig. A1. Pullout load-slip curves of each specimens and the averaged result $\left(500 \mathrm{~mm} / \mathrm{min}, l_{\mathrm{e}}=15 \mathrm{~mm}\right)$.

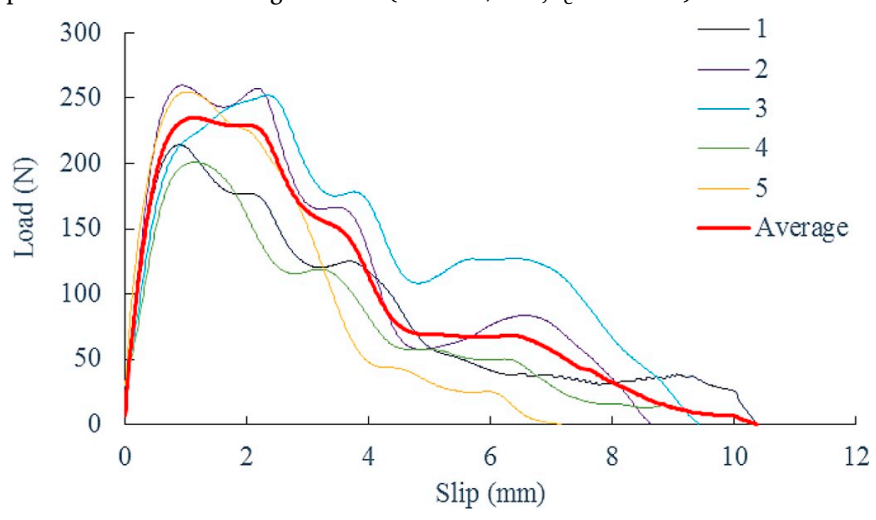

Fig. A2. Pullout load-slip curves of each specimens and the averaged result $\left(1000 \mathrm{~mm} / \mathrm{min}, l_{\mathrm{e}}=10 \mathrm{~mm}\right)$.

\section{References}

[1] H.J.H. Brouwers, H.J. Radix, Self-compacting concrete: theoretical and experimental study, Cem. Concr. Res. 35 (2005) 2116-2136.

[2] Q.L. Yu, P. Spiesz, H.J.H. Brouwers, Development of cement-based lightweight composites - part 1: mix design methodology and hardened properties, Cem. Concr. Compos. 44 (2013) 17-29.

[3] Q.L. Yu, H.J.H. Brouwers, Development of a self-compacting gypsum-based lightweight composite, Cem. Concr. Compos. 34 (2012) 1033-1043.

[4] D.Y. Yoo, N. Banthia, Mechanical properties of ultra-high-performance fiber-reinforced concrete: a review, Cem. Concr. Compos. 73 (2016) 267-280.

[5] D.Y. Yoo, S.T. Kang, Y.S. Yoo, Enhancing the flexural performance of ultra-highperformance concrete using long steel fibers, Compos. Struct. 147 (2016) 220-230.
[6] R. Yu, Development of Sustainable Protective Ultra-High Performance Fibre Reinforced Concrete (UHPFRC)-Design, Assessment and Modeling. PhD thesis. Eindhoven University of Technology. Eindhoven, the Netherlands, 2015.

[7] A. Spasojević, Structural Implications of Ultra-High Performance Fibre-Reinforced Concrete in Bridge Design. PhD thesis. Ingénieur civil diplômée de l'Université de Niš, Serbie et de nationalité serbe, 2008.

[8] Weerheijm et al, Understanding the Tensile Properties of Concrete, Edited by Weerheijm, Woodhead Publishing Limited, J, 2013.

[9] M. Johansson, Structural Behaviour in Concrete Frame Corners of Civil Defence Shelters. PhD thesis, Chalmers University of Technology, Gothenburg, Sweden, 2000 .

[10] Y.S. Tai, Uniaxial compression tests at various loading rates for reactive powder concrete, Theor. Appl. Fract. Mech. 52 (2009) 14-21.

[11] K. Wille, M. Xu, S. El-Tawil, A. Naaman, Dynamic impact factors of strain hardening 
UHP-FRC under direct tensile loading at low strain rates, Mater. Struct. (2014) $1-15$.

[12] S.G. Millard, T.C.K. Molyneaus, S.J. Barnett, X. Gao, Dynamic enhancement of blastresistant ultra high performance fibre-reinforced concrete under flexural and shear loading, Int. J. Impact Eng. 37 (2010) 405-413.

[13] C.Y. Tan, R. Hamid, M. Kasmuri, Dynamic stress-strain behaviour of steel fiber reinforced high-performance concrete with fly ash, Adv. Civ. Eng. (2012), https:// doi.org/10.1155/2012/907431.

[14] N.T. Tran, T.K. Trana, D.J. Kim, High rate response of ultra-high-performance fiberreinforced concretes under direct tension, Cem. Concr. Res. 69 (2015) 72-87.

[15] S. Abdallah, M.Z. Fan, X.M. Zhou, Pull-out behaviour of hooked end steel fibres embedded in ultra-high performance mortar with various W/B ratios, Int. J. Concr. Struct. Mater. (2017), https://doi.org/10.1007/s40069-017-0193-8.

[16] N. Banthia, J.F. Trottier, Deformed steel fiber-cementitious matrix bond under impact, Cem. Concr. Res. 21 (1991) 158-168.

[17] V. Bindiganavile, N. Banthia, Impact response of the fiber-matrix bond in concrete, Can. J. Civ. Eng. 32 (5) (2005) 924-933, https://doi.org/10.1139/105-039.

[18] T. Abu-Lebdeh, S. Hamoush, B. Zornig, Rate effect on pullout behavior of steel fibers embedded in very-high strength concrete, Am. J. Eng. Appl. Sci. 3 (2) (2010) 454-463.

[19] M. Xu, B. Hallinan, K. Wille, Effect of loading rates on pullout behavior of high strength steel fibers embedded in ultra-high performance concrete, Cem. Concr. Compos. 70 (2016) 98-109.

[20] Y.S. Tai, S. El-Tawil, T.H. Chung, Performance of deformed steel fibers embedded in ultra-high performance concrete subjected to various pullout rates, Cem. Concr. Res. 89 (2016) 1-13.

[21] Y.S. Tai, S. El-Tawil, High loading-rate pullout behavior of inclined deformed steel fibers embedded in ultra-high performance concrete, Constr. Build. Mater. 148 (2017) 204-218.

[22] D.Y. Yoo, S. Kim, G.J. Park, J.J. Park, S.W. Kim, Effects of fiber shape, aspect ratio, and volume fraction on flexural behavior of ultra-high-performance fiber-reinforced cement composites, Compos. Struct. 174 (2017) 375-388.

[23] S.H. Park, D.J. Kim, G.S. Ryu, K.T. Koh, Tensile behavior of ultra high performance hybrid fiber reinforced concrete, Cem. Concr. Compos. 34 (2012) 172-184.

[24] Z. Wu, C. Shi, W. He, Effects of steel fiber content and shape on mechanical properties of ultra high performance concrete, Constr. Build. Mater. 103 (2016) 8-14.

[25] J.Z. Liu, F.Y. Han, G. Cui, Q.Q. Zhang, J. Lv, L.H. Zhang, Z.Q. Yang, Combined effect of coarse aggregate and fiber on tensile behavior of ultra-high performance concrete, Constr. Build. Mater. 121 (2016) 310-318.

[26] D.J. Kim, S.E. Tawil, A.E. Naaman, Loading rate effect on pullout behavior of deformed steel fibers, ACI Mater. J. 105 (6) (2008) 576-584.

[27] J.M. Alwan, A.E. Naaman, P. Guerrero, Effect of mechanical clamping on the pullout response of hooked steel fibers embedded in cementitious matrices, Concr. Sci. Eng. 1 (1999) 15-25.

[28] C. Sujivorakul, A.M. Waas, Pullout response of a smooth fiber with an end anchorage, J. Eng. Mech. 126 (9) (2000) 986-993.

[29] F. Laranjeira, C. Molins, A. Aguado, Predicting the pullout response of inclined hooked steel fibers, Cem. Concr. Res. 40 (2010) 1471-1487.

[30] E. Zile, O. Zile, Effect of the fiber geometry on the pullout response of mechanically deformed steel fibers, Cem. Concr. Res. 44 (2013) 18-24.
[31] P.P. Li, Q.L. Yu, H.J.H. Brouwers, Effect of coarse basalt aggregates on the properties of Ultra-high Performance Concrete (UHPC), Constr. Build. Mater. 170 (2018) 649-659.

[32] Y.Y.Y. Cao, Q.L. Yu, Effect of inclination angle on hooked end steel fiber pullout behavior in ultra-high performance concrete, Compos. Struct. 201 (2018) 151-160.

[33] X.H. Wang, K.J. Wang, P. Taylor, G. Morcous, Assessing particle packing based selfconsolidating concrete mix design method, Constr. Build. Mater. 70 (2014) 439-452.

[34] K. Wille, A.E. Naaman, Pullout behavior of high-strength steel fibers embedded in ultra-high-performance concrete, Mater. J. 109 (46) (2012) 479-488.

[35] L.J. Malvar, C.A. Ross, Review of strain rate effect for concrete in tension, ACI Mater. J. 95 (6) (1998) 735-739.

[36] J. Weerheijm, J.C.A.M. Van Doormaal, Tensile failure of concrete at high loading rates: new test data on strength and fracture energy from instrumented spalling tests, Int. J. Impact Eng. 34 (3) (2007) 609-626.

[37] A. Brara, J.R. Klepaczko, Dynamic tensile behaviour of concrete; experiment and numerical analysis, ACI Mater. J. 101 (02) (2004) 162-167.

[38] A. Brara, J.R. Klepaczko, Experimental characterization of concrete in dynamic tension, Mech. Mater. 38 (2006) 253-267.

[39] Thomas T. (1993). CEB-FIB Model Code 1990. Lausanne, Switzerland, design code edition.

[40] Y.B. Lu, Q.M. Li, About the dynamic uniaxial tensile strength of concrete-like materials, Int. J. Impact Eng. 38 (4) (2011) 171-180.

[41] C.A. ROSS, D.M. Jerome, J.W. Tedesco, M.L. Hughes, Moisture and strain rate effect on concrete strength, ACI Mater. J. 93 (1996) 293-300.

[42] I. Vegt, Concrete in Dynamic Tension: The Fracture Process. PhD thesis, Delft University of Technology. Delft, the Netherlands, 2016.

[43] H.W. Reinhardt, J. Weerheijm, Tensile fracture of concrete at high loading rates taking account of inertia and crack velocity effects, Int. J. Fract. 51 (1991) 31-42.

[44] J. Ožbolt, A. Sharma, H. Reinhardt, Dynamic fracture of concrete - compact tension specimen, Int. J. Solids Struct. 48 (2011) 1534-1543.

[45] H.A.B. Othman, Performance of Ultra-High Performance Fibre Reinforced Concrete Plates Under Impact Loads. PhD thesis, Ryerson University, Toronto, Canada, 2016.

[46] R.J. Thomas, A.D. Sorensen, Review of strain rate effects for UHPC in tension, Constr. Build. Mater. 153 (2017) 846-856.

[47] A. Filiatrault, M. Holleran, Stress-strain behavior of reinforcing steel and concrete under seismic strain rates and low temperatures, Mater. Struct. 34 (2001) 235-239.

[48] U.N. Gokoz, A.E. Naaman, Effect of strain-rate on the pull-out behaviour of fibres in mortar, Int. J. Cem. Compos. Light. Concr. 3 (3) (1981) 187-202.

[49] R. Ranade, V.C. Li, W.F. Heard, Tensile rate effects in high strength-high ductility concrete, Cem. Concr. Res. 68 (2015) 94-104.

[50] S. Pyo, K. Wille, S. El-Tawil, A.E. Naaman, Strain rate dependent properties of ultra high performance fiber reinforced concrete (UHP-FRC) under tension, Cem. Concr. Compos. 56 (2015) 15-24.

[51] M. Xu, K. Wille, Fracture energy of UHP-FRC under direct tensile loading applied at low strain rates, Compos. Part B 80 (2015) 116-125.

[52] S.H. Park, G.S. Ryu, K.T. Koh, D.J. Kim, Effect of shrinkage reducing agent on pullout resistance of high-strength steel fibers embedded in ultra-high-performance concrete, Cem. Concr. Compos. 49 (2014) 59-69.

[53] Y.P. Geng, C.K.Y. Leung, Damage-based modeling of fiber pullout under variable compressive stress, J. Eng. Mech. 123 (1997) 342-349. 